ORIGINAL ARTICLE

\title{
Crisis management during anaesthesia: cardiac arrest
}

\author{
W B Runciman, R W Morris, L M Watterson, J A Williamson, A D Paix
}

Qual Saf Health Care 2005;14:e14 (http://www.qshc.com/cgi/content/full/14/3/e14). doi: 10.1136/qshc.2002.004473

Background: Cardiac arrest attributable to anaesthesia occurs at the rate of between 0.5 and 1 case per 10000 cases, tends to have a different profile to that of cardiac arrest occurring elsewhere, and has an inhospital mortality of $20 \%$. However, as individual practitioners encounter cardiac arrest rarely, the rapidity with which the diagnosis is made and the consistency of appropriate management varies considerably. Objectives: To examine the role of a previously described core algorithm "COVER ABCD-A SWIFT CHECK", supplemented by a sub-algorithm for cardiac arrest, in the management of cardiac arrest occurring in association with anaesthesia.

Methods: The potential performance of this structured approach for each the relevant incidents among the first 4000 reported to the Australian Incident Monitoring Study (AIMS) was compared with the actual management as reported by the anaesthetists involved.

Results: There were 129 reports of cardiac arrest associated with anaesthesia among the first 4000 AIMS incident reports. Identified aetiological factors were grouped into five categories: (1) anaesthetic technique (11 cases with this category alone; 32 with this and one or more of the other categories, representing $25 \%$ of all 129 cardiac arrests); (2) drug related $(16 ; 32,25 \%)$; (3) associated with surgical procedure $(9 ; 29$, $22 \%) ;(4)$ associated with pre-existing medical or surgical disease $(30 ; 82,64 \%)$; $(5)$ unknown $(8 ; 14$, $11 \%)$. The "real life" presentation and management of cardiac arrest in association with anaesthesia differs substantially from that detailed in general published guidelines. Cardiac rhythms at the time were

See end of article for authors' affiliations

Correspondence to:

Professor W B Runciman President, Australian Patient Safety Foundation GPO Box 400, Adelaide, South Australia 5001, Australia; research@apsf. net.au

Accepted 11 January 2005 sinus bradycardia (23\%); asystole (22\%); tachycardia/ventricular tachycardia/ventricular fibrillation (14\%); and normal (7\%), with a further third unknown. Details of treatment were recorded in 110 reports; modalities employed included cardiac compression (72\%); adrenaline (61\%); 100\% oxygen (58\%); atropine $(38 \%)$; intravenous fluids $(25 \%)$, and electrical defibrillation $(17 \%)$. There were no deaths or permanent morbidity in the 11 cases due solely to anaesthetic technique. 24 of the 25 deaths occurred in patients with significant pre-existing medical or surgical disease.

Conclusion: Because there are often multiple contributing factors to a cardiac arrest under anaesthesia, a complete systematic assessment of the patient, equipment, and drugs should be completed. The "COVER ABCD-A SWIFT CHECK" algorithm was judged to be a satisfactory process in this context and should be carried out even if the cause of the cardiac arrest is already thought to have been found. The diagnosis and management of cardiac arrest in association with anaesthesia differs considerably from that encountered elsewhere. The outcome is generally good, with most patients leaving hospital alive and apparently well.

$\mathrm{F}$ ive major studies of cardiac arrest in association with anaesthesia have been published in the last few years. These relate to over 500000 cases of all ages in the $\mathrm{USA}^{1{ }^{12}}$ one million paediatric cases in the USA, ${ }^{3} 2.3$ million cases in Japan, ${ }^{4}$ and over 100000 in France. ${ }^{5}$ The findings are remarkably consistent. Cardiac arrest attributable to anaesthesia occurred at the rate of between 0.5 and 1 case per 10000 cases overall and at the rate of 1.4 per 10000 cases for the paediatric series; $55 \%$ of these were in children less than 1 year of age. The overall rate of cardiac arrest is up to 10 times higher than this, with uncontrolled bleeding, technical surgical problems, extensive co-morbidity, and advanced age all featuring prominently. In-hospital mortality in the anaesthesia related group was considerably lower than the surgical rate, with $80 \%$ of these patients leaving hospital. Most of the anaesthesia related cardiac arrests were thought to be preventable and to have involved human error or inadequate human resources. It was therefore thought to be worthwhile to examine the cases of cardiac arrest from the Australian Incident Monitoring Study (AIMS) to identify aetiological and associated factors, to determine to what extent the actual management reported conformed to recommended guidelines, and to examine whether a structured approach would be better. To this end, cases of cardiac arrest among the first 4000 incidents reported to AIMS were

examined in detail and are presented here. Some of the cases in this review were included in a previously published review. ${ }^{6}$

In 1993 a "core" crisis management algorithm represented by the mnemonic COVER ABCD-A SWIFT CHECK (the AB precedes COVER for the non-intubated patient) was proposed as the basis for a systematic approach to any crisis during anaesthesia where it is not immediately obvious what should be done or where actions taken have failed to remedy the situation. ${ }^{7}$ This was validated against the first 2000 incidents reported to the AIMS. AIMS is an ongoing study which involves the voluntary anonymous reporting of any unintended incident which reduced or could have reduced the safety margin for a patient. ${ }^{8}$

It was concluded that, if this algorithm had been correctly applied, a functional diagnosis would have been reached in $40-60$ seconds in $99 \%$ of applicable incidents and that the learned sequence of actions recommended by the COVER portion would have led to appropriate steps being taken to handle the $60 \%$ of problems relevant to this portion of the algorithm. ${ }^{7}$ However, this study also showed that the $40 \%$ of problems represented by the remainder of the algorithm ABCD-A SWIFT CHECK were not always promptly diagnosed or appropriately managed..$^{7-9}$ It was decided that it would be useful, for these remaining problems, to develop a set of 


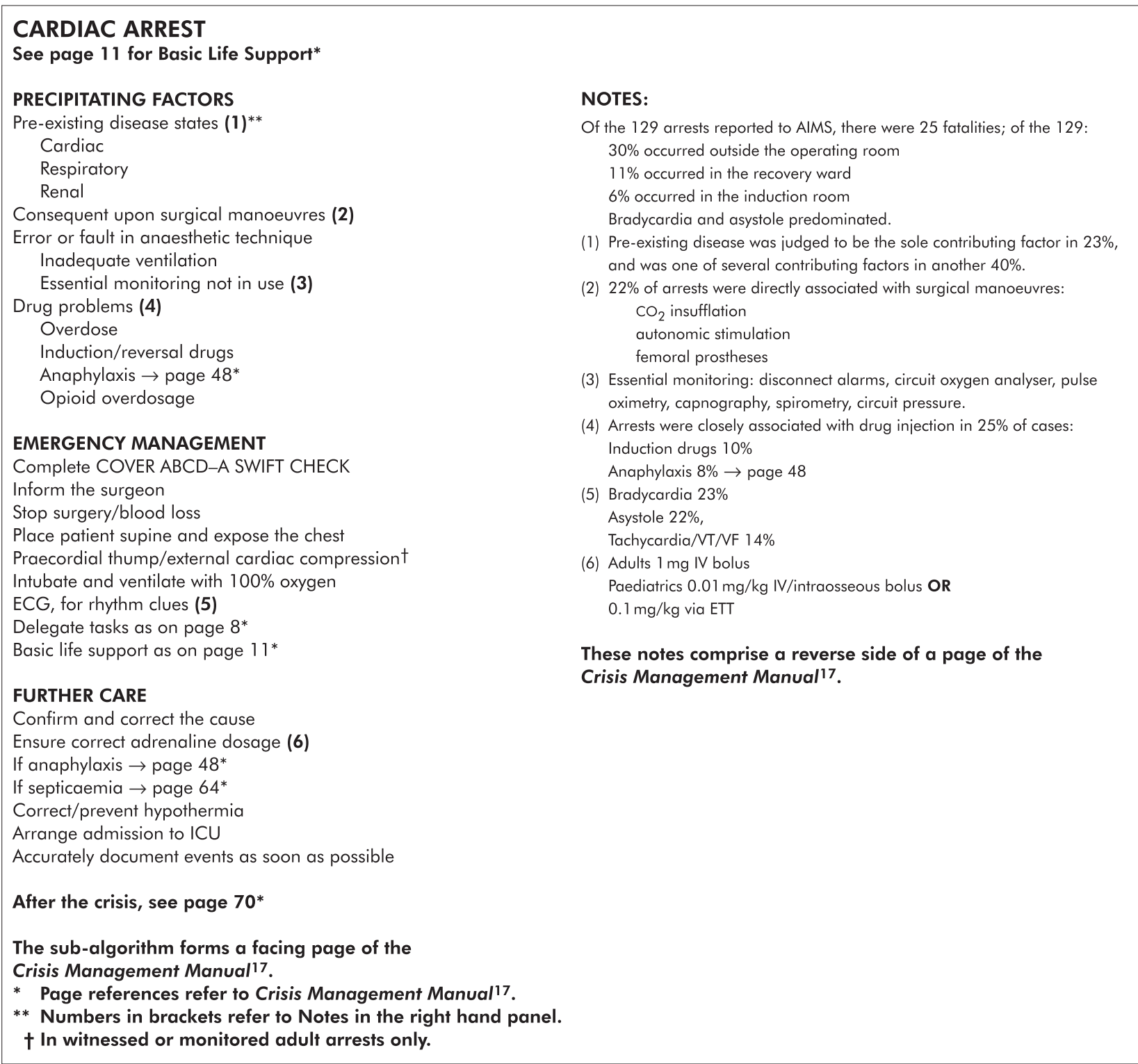

Figure 1 Cardiac arrest.

sub-algorithms in an easy-to-use crisis management manual. ${ }^{10}$ This study reports on the potential place of the COVER ABCD-A SWIFT CHECK algorithm in the diagnosis and initial management of cardiac arrest and provides an outline of a specific crisis management sub-algorithm for cardiac arrest during anaesthesia.

\section{METHODS}

Incidents among the first 4000 reported to AIMS which had the key words "cardiac arrest", "death", "circulatory collapse", and "pulseless" were selected for analyses of the underlying and precipitating factors and for factors which may have contributed to the problem. The sequences of actions taken by the anaesthetist were also examined. It was assumed that, if anything was not documented, it was not done. In this series "CPR" was taken to mean external cardiac compression (ECC) alone. Cases of intentional cardiac arrest associated with cardiac surgery were excluded. The diagnosis of cardiac arrest was made if the patient was reported as pulseless or if the electrocardiograph (ECG) showed asystole. Incidents where the anaesthetist had no control were excluded from the main review.

\section{Contributing factors}

Incidents were assigned to one or more of five categories of aetiological factors:

- anaesthetic technique, e.g. circuit disconnection;

- drug related, e.g. narcotic overdose or anaphylaxis;

- associated with surgical technique, e.g. reaction to reaming or cementing the femoral shaft;

- pre-existing medical or surgical disease, e.g. sepsis or trauma;

- unknown: there was a group of incidents involving patients with pre-existing medical or surgical disease who arrested during routine and seemingly appropriate anaesthesia and surgery. Although in these incidents the anaesthesia and/or surgery presumably precipitated the arrest, the arrest was not attributed to any of the first three categories. 
Because of uncertainty about which other specific subalgorithm should have been combined with the recommendations for cardiac arrest, no attempt was made to judge how often applying the Crisis Management Manual ${ }^{10}$ to each situation would have led to a better outcome. However, following the sub-algorithm in fig 1 would not have done any harm and may have led to a more rapid resolution of the problem in several cases.

\section{RESULTS}

There were 142 cardiac arrests that satisfied the diagnostic criteria. Thirteen were excluded from the main series and are only briefly reported on, leaving 129 cardiac arrests associated with anaesthesia for detailed review. The majority of arrests $(88 \%)$ occurred in the operating theatre suite; the remainder occurred in the intensive care unit, the general ward, an imaging room, or in transit (table 1). The results for the 129 arrests are reported under the headings of aetiological factors, diagnosis, management, and outcome.

\section{Aetiological factors}

Table 2 shows the number of incidents in each category. There were 74 incidents (57\%) where only one aetiological factor was thought to have contributed to the arrest; in the remaining $43 \%$ of incidents there was thought to have been more than one aetiological factor-for example, air embolus and endobronchial intubation. Thirty (mostly elderly) patients with pre-existing medical conditions arrested in association with routine and appropriate anaesthesia and unremarkable surgery. A routine anaesthetic and surgical procedure in eight healthy patients resulted in cardiac arrest in the absence of any other identified contributing factors.

\section{Anaesthetic technique}

Eleven patients arrested because of problems associated with anaesthetic technique alone: circuit disconnection, hypoxia in transit to the recovery room, ventricular fibrillation (VF) during Swan-Ganz catheter insertion, endobronchial intubation, inadequate blood replacement, caval compression from a kidney rest, narcotic pump procedure error, excessive epidural air (or intravenous air) in an infant, obstruction to expiration from a herniated endotracheal tube (ETT) cuff, obstructed airway during bronchoscopy, and VF during subclavian catheter insertion.

A further 21 patients arrested because of anaesthetic technique in combination with other aetiological factors. The problems with the anaesthetic technique in these were: inadequate ventilation in transit $(n=5)$, inadequate blood replacement $(n=2)$, high spinal $(n=2)$, intraoperative aspiration of vomit, discharged from recovery room to general ward arrested and died 2 hours later, multiple large vessel punctures during attempted central venous cannulation in an infant, oesophageal intubation, poor mask fit because of nasal cannulae, postoperative stridor, intravascular bupivacaine and adrenaline, airway obstruction, inadequate ventilation, trolley positioned steep head down following spinal

\begin{tabular}{lc} 
Table 1 & Locations of reported cardiac arrests \\
\hline Locations & No (\%) \\
\hline Operating room & $91(71)$ \\
Recovery room & $14(11)$ \\
Induction room & $9(6)$ \\
Intensive care & $6(5)$ \\
General ward & $5(4)$ \\
Imaging room & $2(2)$ \\
In transit & $2(2)$ \\
\hline
\end{tabular}

anaesthesia, excessive "break" in operating table, vomited and probably aspirated during surgery under arm block, and pneumoperitoneum with head up tilt in a patient taking phenothiazines.

\section{Drug related}

Thirty two arrests occurred in close temporal relationship to the administration of drugs. Thirteen of these were at induction of anaesthesia and manifested as pulselessness or asystole; several drugs were involved making identification of the specific drug difficult, but suxamethonium was associated with nine of these cases. Four arrests were associated with the administration of neostigmine. Four were associated with antibiotics, three with flucloxacillin and one with vancomycin. Six appeared to be the result of narcotic overdose. A directly and continuously supervised patient in the recovery room was given increments of fentanyl for severe pain, became apnoeic, and arrested.

There were 10 anaphylactic reactions: three with flucloxacillin, two with suxamethonium, two with alcuronium, two with Haemaccel, and one with thiopentone. There were no anaphylactic reactions from "modern" relaxant drugs, although many other patients in this series who had received these drugs had life threatening bradycardias. ${ }^{11}$

Several sick patients collapsed immediately after intravenous induction of anaesthesia where there was no specific identifiable drug-related problem. The choice of intravenous induction agent did not seem to be very important and arrests occurred with propofol, ketamine, thiopentone, midazolam and fentanyl.

There were several cases in which residual neuromuscular blockade with paralysis was implicated. There appeared to be some inappropriate interpretation of tests suitable for adequacy of reversal of muscle paralysis. For example, one report used the words "despite full train of four (TOF)". The ability of the patient to sustain a contraction with a $50 \mathrm{~Hz}$ stimulus would be a more specific test for return of adequate muscle function.

\section{Associated with surgical technique}

Twenty nine arrests were directly associated with a surgical manoeuvre-for example, six with the insufflation of carbon dioxide by the surgeon; five with autonomic stimulation (traction on or dilatation of structures); four with reaming or insertion of a prosthesis into the femur; three with the application of suction to intracranial drains; one with the inflation of a tourniquet.

\section{Pre-existing medical or surgical disease}

There were 30 patients who arrested in association with apparently routine anaesthesia and unremarkable surgery in whom the only contributing factor was pre-existing medical or surgical disease. There were an additional 52 patients in whom this was only one of several contributing factors. The range of pre-existing diseases associated with cardiac arrest included rare conditions and congenital abnormalities but mostly were forms of cardiac, respiratory or renal failure. One arrest occurred in a patient who failed to take routine cardiovascular medications.

Three arrests occurred in circumstances of psychological stress. In one case an inexperienced surgeon collapsed when confronted with an open chest full of blood. A patient with stable angina following a myocardial infarction 18 years previously, taking nifedipine, nitrates and atenolol, was given temazepam as a premedication. He was awake and talking in the lift on the way to the operating theatre. On arrival he suddenly collapsed. Resuscitation was rapidly started and was initially successful but he ultimately died. The third case was a man who fainted in a chair while an epidural was put 
Table 2 Aetiological factors among 129 incidents of cardiac arrest

\begin{tabular}{lccc}
\hline & $\begin{array}{c}\text { Single } \\
\text { factor }\end{array}$ & $\begin{array}{l}\text { One or more } \\
\text { factors }\end{array}$ & $\begin{array}{c}\% \text { of all } 129 \text { incidents with } \\
\text { the contributing factor }\end{array}$ \\
\hline $\begin{array}{l}\text { Anaesthetic technique } \\
\text { Drug related }\end{array}$ & 11 & 32 & 25 \\
Associated with surgical procedure & 16 & 32 & 25 \\
Associated with pre-existing medical or & 30 & 29 & 22 \\
surgical conditions & 8 & 82 & 11 \\
Unknown (healthy patients) & 74 & 14 & 57 \\
Total single factors & & 64 \\
The number of incidents associated with only one category is shown in the first column and the number of incidents \\
in which this category was involved, either alone or in combination with other contributory factors, is shown in the \\
second column. The percentage of all 129 incidents associated with each category is shown in the last column.
\end{tabular}

in for his partner in labour; he was given ECC for a brief period.

\section{Unknown}

There were eight arrests where the aetiology could not be determined, including one fit young man having a routine appendicectomy.

\section{Regional or local anaesthesia}

There were 25 arrests in this series (19\% of all arrests) in association with major regional anaesthetic blocks (spinal, epidural, arm or eye blocks). As previously stated, there was one death from vomiting and presumed aspiration following an arm block. Several patients collapsed during insertion of a regional anaesthetic block (spinal, epidural or eye block). The aetiology was seldom clear but may have included the effects of sedation, pre-existing disease, inadvertent intravascular injection, and positioning.

\section{Incidents not included in review}

There were 10 deaths from uncontrollable bleeding from trauma or from surgery. Some of the patients arrested during placement of intravascular monitoring lines prior to surgery. There was one death in a young patient with an altered conscious state who was sedated in an imaging room in the absence of an anaesthetist. There was one patient who was pulseless from intense vasoconstriction who had an intraarterial line inserted and the blood pressure was 280/ $110 \mathrm{~mm} \mathrm{Hg}$. He was given glyceryl trinitrate and the depth of anaesthesia was deepened. As previously stated, there was one incident associated with neither anaesthesia nor surgery-a man who fainted in a chair while an epidural was put in for his partner in labour, who was given ECC for a brief period.

\section{Diagnosis}

The diagnosis of cardiac arrest in association with anaesthesia is problematic for two reasons. Firstly, there is a continuous range of reduction of cardiac output which makes it difficult to determine the point at which it becomes significant. This problem was particularly evident with anaphylaxis (patients given 100\% oxygen, adrenaline and fluids but not ECC and defibrillation were excluded from this review even though the blood pressure was very low). In the few patients in this review who had intra-arterial pressure monitoring in place at the time of cardiac arrest, the impression was gained that, because a pressure trace was visible on the monitor, the anaesthetist was less inclined to manage the patient as a cardiac arrest. Secondly, an arbitrary decision has to be made about what constitutes a significant duration of arrest. For example, should a vagal arrest of 30 seconds with prompt recovery be counted? The diagnosis should be made at the $\mathrm{C}$ stage of COVER, although other factors (listed below) often precede or accompany pulselessness

\section{ECG rhythm}

The ECG rhythm at the time of the arrest was reported in 86 cases $(67 \%)$. Table 3 shows that bradycardias were reported much more commonly than tachycardias. ${ }^{11}$ There were nine cases in which the ECG was explicitly stated to be normal but the patient was pulseless, highlighting the insensitivity of the ECG as an index of cardiac function. The ECG rhythm was tachycardia or ventricular fibrillation in only $14 \%$ of patients. Bizarre ventricular rhythms, ventricular extra beats, ventricular tachycardia, or ventricular fibrillation were all mentioned and appeared to be particularly associated with irritation of the surface of the heart muscle-for example, dissection of epicardial adhesions or insertion of a SwanGanz catheter.

\section{Oxygen desaturation}

There were 29 reports in which details of both the ECG rhythm and the oxygen saturation were included (table 4).

The desaturation group (saturation $<90 \%$ ) includes both those where the numerical saturation value was recorded and those described as blue or cyanosed. However, in all patients reported here as having saturations $\geqslant 90 \%$, the actual reading was included in the report. Twelve reports specifically mentioned that the oximeter measurement was unreliable at the time, although in two cases the "poor signal" alarm first alerted the anaesthetist. Eleven of the 29 were associated with hypoxaemia and the rest were associated with other causes, mostly direct drug effects and autonomic stimulation. Although one case of circuit disconnection presented as progressive and severe bradycardia (before the routine use of oximetry), no obvious association with irregular rhythm or asystole was reported. This confirms yet again the lack of value of the ECG as an indicator of hypoxaemia.

\section{Capnography}

Eleven reports mentioned capnography. In three reports the capnography waveform and end-tidal value was normal even though the patient was pulseless, suggesting that normal

Table 3 ECG rhythm at time of cardiac arrest (where known)

\begin{tabular}{lc}
\hline ECG rhythm & No (\%) \\
\hline Bradycardia & $30(23)$ \\
Asystole & $29(22)$ \\
Tachycardia/VT/VF & $18(14)$ \\
Normal & $9(7)$ \\
Not indicated & $43(33)$ \\
\hline \multirow{2}{*}{ VT, ventricular tachycardia; VF, ventricular fibrillation. }
\end{tabular}




\begin{tabular}{|c|c|c|}
\hline \multirow[b]{2}{*}{ ECG rhythm } & \multicolumn{2}{|c|}{ Oximeter reading } \\
\hline & $<90 \%$ & $\geqslant 90 \%$ \\
\hline Bradycardia & 6 & 3 \\
\hline Asystole & 5 & 2 \\
\hline Tachycardia/VT/VF & 4 & 1 \\
\hline Normal & 5 & 1 \\
\hline Other & 1 & 1 \\
\hline Total & 21 & 8 \\
\hline
\end{tabular}

pulmonary blood flow may continue in the presence of extremely low systemic arterial pressure.

\section{Monitoring in transit}

Six arrests occurred between the end of anaesthesia (when all the monitoring had been removed) and arrival in the recovery room when the patient was again monitored.

\section{Depression of conscious state}

In four patients depressed conscious state was the first indicator of inadequate circulation. One patient, previously awake in the operating room, was found to be unconscious on arrival in the recovery room. Another lost consciousness in the recovery room and two others lost consciousness during regional anaesthesia.

\section{Management}

Basic details of management were provided in 110 of the 129 reports. In $28 \%$ of these patients cardiac compression was not performed. No assumptions were made about data where it was incomplete and, as a consequence, there is almost certainly significant distortion of the figures-for example, for the frequency of intravenous fluid loading as part of the management.

\section{Immediate management}

Six specific aspects of management are listed in descending order of reported use (table 5):

- cardiac compression;

- adrenaline;

- ventilation with $100 \%$ oxygen;

- atropine;

- intravenous fluids;

- defibrillation.

Other drugs and measures were directed at specific causes. External cardiac compression was performed in 79 patients $(72 \%)$. There was delay in the performance of ECC in two patients because of the need to change the position of the patient from lateral to supine.

Adrenaline was given to 67 of the 110 patients $(61 \%)$. Administration was usually by intermittent bolus with an infusion rarely being employed. One patient who suffered repeated episodes of hypotension was given repeated boluses and may have benefited from an infusion. The initial dose administered was recorded in 42 cases and was $100 \mu \mathrm{g}$ or less in $13(30 \%) ; 100-1000 \mu \mathrm{g}$ in 21 patients $(50 \%)$, and more than $1 \mathrm{mg}$ in eight patients (19\%) (these figures include only adult patients).

Several patients were given " $100 \%$ oxygen" with a Hudson mask which is an air entrainment device that actually delivers no more than $60 \%$ inspired oxygen to spontaneously breathing patients only.

\begin{tabular}{lc}
$\begin{array}{l}\text { Table } 5 \\
\text { arrests associated with anaesthesia }(n=110)^{*}\end{array}$ \\
\hline Intervention & No (\%) \\
\hline External cardiac compression & $79(72)$ \\
Adrenaline & $67(61)$ \\
$100 \%$ oxygen & $64(58)$ \\
Atropine & $42(38)$ \\
IV fluid & $27(25)$ \\
Defibrillation & $19(17)$ \\
\hline *Most arrests involved more than one intervention.
\end{tabular}

Atropine was given to 41 patients (37\%); the dose was recorded in 20 of these and ranged from 0.1 to $1.2 \mathrm{mg}$.

Nineteen patients were defibrillated; the initial charge was recorded in 13. One patient who weighed $125 \mathrm{~kg}$ developed anaphylaxis and, after $300 \mu \mathrm{g}$ of intravenous adrenaline, went into VF and after defibrillation with 100 Joules went into sinus rhythm.

Other drugs used in the management of patients developing cardiac arrest are shown in table 6. Bicarbonate was given in five cases. It was given early in the resuscitation of two patients, soon after intubation following asystole from a high spinal in a severe asthmatic and after suxamethonium in a patient with a 5 week old head injury and a serum potassium level of $9.2 \mathrm{mmol} / \mathrm{l}$. It was given once during asystole after hypoxia from airway obstruction and twice during prolonged resuscitation, in one case "guided by blood gas analysis". Calcium was given in four cases: after suxamethonium in a paraplegic, after severe bradycardia associated with reaming of a femur in a patient with disseminated carcinoma, after hypoxic asystole from airway obstruction, and during rapid blood replacement. Magnesium was given to one malnourished patient with carcinoma of the pyriform fossa and a left ventricular ejection fraction of $25 \%$ who developed runs of ventricular tachycardia following induction and intubation.

\section{Measures directed at specific causes}

Head down tilt was used in a case of gas embolus. The break in the operating table was removed in a case of suspected caval occlusion during a ureterolithotomy. An emergency thoracotomy was performed in two patients for the management of pulmonary embolus and to secure the airway in a case of tracheal rupture. Autonomic stimulation was stopped in several cases such as extraocular muscle traction and release of carbon dioxide from the peritoneal cavity.

\begin{tabular}{lc|}
\hline Table 6 & Other drugs used in management \\
\hline Drug & No \\
\hline Lignocaine (lidocaine) & 12 \\
Ephedrine & 7 \\
Naloxone & 6 \\
Bicarbonate & 5 \\
Calcium & 4 \\
Dopamine & 4 \\
Isoprenaline & 3 \\
Metaraminol & 3 \\
Atenolol & 2 \\
Hydrocortisone & 2 \\
Aminophylline & 1 \\
Glyceryl trinitrate & 1 \\
Inotropes & 1 \\
Magnesium & 1 \\
Prochlorperazine & 1 \\
Salbutamol & 1 \\
\hline
\end{tabular}




\begin{tabular}{lc} 
Table 7 & Outcome of cardiac arrest \\
\hline Outcome & No (\%) \\
\hline Death & $25(19)$ \\
Morbidity & $3(2)$ \\
Recovered* & $101(78)$
\end{tabular}

There were no deaths in the 11 cases where anaesthetic technique was the sole contributing factor *Without significant morbidity.

Follow up management

Major complications of resuscitation occurred in several cases such as fractured ribs, pneumothorax, and pulmonary oedema. Elective surgery was continued following resuscitation in some cases.

\section{Outcome}

There were 25 deaths (19\%) in this series of 129 cardiac arrests. Three patients suffered morbidity and the remaining 101 patients $(78 \%)$ recovered (table 7$)$. There were no deaths in the 11 patients who arrested because of anaesthetic technique alone (one suffered temporary morbidity but was "fully recovered" at 48 hours). Pre-existing medical or surgical disease was one of the aetiological factors in 24 deaths, anaesthetic technique in five, surgery in four, and drugs in one.

\section{DISCUSSION}

The "real life" presentation and management of cardiac arrest in association with anaesthesia appears to differ substantially from that detailed in general published guidelines. ${ }^{12-14}$ The pattern of aetiological factors is different, as are the prevailing cardiac rhythms, with bradycardias and asystole predominating. Anaesthetised patients are better monitored and the diagnosis is generally made early.

\section{Diagnosis}

The traditional guidelines for diagnosis are to assess the conscious state, then check the Airway, Breathing and Circulation $(\mathrm{ABC}){ }^{12-14}$ Depression of conscious state was the presenting sign in only $3 \%$ of cases in this review. It was very useful if present, but it was usually obscured by drug effects. During anaesthesia, airway obstruction is rarely first diagnosed-as suggested in the AHA guidelines ${ }^{12}$ - by a fall in gas flow in and out of the lungs. It is usually diagnosed because of cyanosis or a fall in oxygen saturation. Early detection and impairment of the patient's ability to breathe and to maintain a satisfactory circulation is an integral part of anaesthetic practice. If monitoring devices indicate cardiac arrest, this should always be confirmed by clinical examination. The pulse should be felt, the chest examined with a stethoscope for breath and heart sounds, and the central skin colour assessed. This will identify and exclude a flat ECG which is disconnected and an absent peripheral pulse due to intense vasoconstriction.

Cardiac arrest may not be suspected if the oximeter signal is poor, if the ECG looks normal, or if the arterial pressure trace is present but the pressure is low. In these situations the circulation may be dangerously inadequate and delay in diagnosis may occur. The patient's pulse should be felt in all these situations and the oximeter probe should be removed from the patient and the oximeter function confirmed by placing it on your own finger. Once cardiac arrest is detected, because there are often multiple aetiological factors a complete systematic assessment of the patient, equipment and drugs should be completed (COVER ABCD-A SWIFT CHECK) even if a cause has already thought to have been found.

\section{Management}

It was evident in many reports from the data reported to AIMS that management of cardiac arrest in association with anaesthesia tends to be less aggressive than that recommended in the guidelines. Perhaps anaesthetists are concerned by the hazards of treatment, especially during surgery in progress. Administration of $100 \%$ oxygen leads to awareness in some cases although, clearly, oxygen should be administered in an inspired concentration of $100 \%$ in all cases of cardiac arrest. Knowledge of appropriate oxygen circuits and their use continues to be lacking. Adrenaline easily causes hypertension, myocardial ischaemia, and pulmonary oedema. Many of the patients given adrenaline received intermittent intravenous injections with consequent cardiovascular instability when an infusion would have been more appropriate. The preparation of an adrenaline infusion is an appropriate task for delegation. Cardiac compression may result in trauma to the heart, lungs, or chest wall with life threatening pneumothorax but, clearly, should not be delayed if indicated. The risk of continuing with surgery after ECC or defibrillation needs careful consideration.

\section{Algorithms}

Detailed didactic branching algorithms for diagnosis and management are not always appropriate for cardiac arrest in association with anaesthesia because there are often multiple factors contributing to the aetiology. Anaesthetists use past experience and pattern recognition to make the diagnosis and tailor the management to the circumstances. This is recognised in the AHA guidelines: "Although the algorithms provide a good cookbook, the patient always requires a thinking cook". ${ }^{12}$ However, because of the large number of potential aetiological factors, checklists for management should be used if the expected response is not obtained immediately. Detailed branching flow charts on one page cannot adequately cover the complexity of cardiac arrest in association with anaesthesia and surgery and are difficult to follow quickly. It was judged that adherence to the sequence of actions listed in fig 1 -with appropriate use of the other sequences recommended, depending on the circumstanceswould mean that the necessary measures would virtually always be undertaken.

\section{Delegation of tasks}

The lone anaesthetist must immediately summon help. Effective management depends on clear direction and task delegation by a leader, but in most cardiac arrest situations this still does not occur. An aid to task delegation would be to have tear-out pages of instructions for the anaesthetist in charge to give to other personnel to implement.

\section{Regional anaesthesia}

Collapse during insertion of major regional blocks might be less likely if careful attention is given to correction and maintenance of circulating blood volume (especially in the sitting patient) and if there is heightened awareness that, in the lateral position for spinal or epidural injection, restriction to breathing and caval compression may occur. Careful monitoring during this period seems advisable (refer also to the paper on regional anaesthesia in this series ${ }^{15}$ ).

There were four deaths in association with epidural analgesia in which the diagnosis of intra-abdominal bleeding was concealed. These cases all involved pre-existing cardiovascular disease; major abdominal surgery; combined epidural and general anaesthesia; postoperative epidural analgesia; increasing oliguria; hypotension; collapse and unsuccessful resuscitation. Attention should be given to the careful selection of patients for epidural analgesia and 


\section{Key messages}

- Among the first 4000 anaesthesia incidents reported to AIMS there were 129 cases of cardiac arrest (3\%).

- Identified aetiological factors were: anaesthetic technique, drug related, association with the surgical procedure, association with pre-existing disease, and "unknown". Each factor could be further divided between "that cause acting alone" or "in combination with one or more of the other causes".

- The majority of arrests ( $88 \%$ ) occurred in the operating theatre suite.

- The most common aetiological factors - whether acting alone or in combination with other factors - were "preexisting medical or surgical conditions" followed by "drug related causes" and then "anaesthetic technique".

- This series re-emphasises the fact that the "real life" presentation and the management of cardiac arrest in association with general anaesthesia differs substantially and positively from that detailed in general published guidelines. These guidelines require modification and extension for use during anaesthesia and in recovery.

- 24 of the 25 deaths in this series occurred in patients with significant pre-existing medical or surgical disease. Four of these were with epidural anaesthesia in the presence of concealed intra-abdominal bleeding. There were no deaths or permanent morbidity in the 11 cases due solely to anaesthetic technique.

- Specific management procedures (in descending order of frequency) were: compression, adrenaline, 100\% oxygen, atropine, IV fluid, and defibrillation.

- If monitoring devices indicate cardiac arrest, this must always be confirmed by direct clinical examination.

- The often multiple contributing factors to a cardiac arrest during anaesthesia require complete assessment of patient, equipment, and drugs. The use of the core algorithm COVER ABCD-A SWIFT CHECK was considered to be a satisfactory means to this end and should be used even when the cause of the arrest is thought to have been identified.

provision of appropriately trained postoperative staff and facilities for such procedures.

\section{Monitoring in transit}

Six arrests occurred between the end of the anaesthesia when monitoring had been removed and arrival in the recovery room when the patient was adequately reassessed. Clinical monitoring during transit tends to be distracted by other factors at this time. Adherence to lighting standards is important. Routine portable oximetry has a valuable place here. The practice of a sole anaesthetist acting as both clinician and porter is to be discouraged.

\section{Follow up}

Finally, it is important that a full explanation of what happened be given to the patient and the problem clearly documented in the anaesthetic record. If a particular precipitating event was significant or a particular action was useful in resolving the crisis, this should be clearly explained and documented.

\section{CONCLUSION}

The diagnosis and management of cardiac arrest in association with anaesthesia differs significantly from that encountered elsewhere. ${ }^{16}$ Based on the 129 incidents in this review, present general guidelines for the assessment and management of the patient who suffers a cardiac arrest need modification and extension for use during anaesthesia. Anaesthetists in training should be specifically instructed and practising anaesthetists regularly refreshed in the particular problems of the diagnosis and management of cardiac arrest in association with anaesthesia. ${ }^{17}$

The differences from non-anaesthetic cardiac arrest should be emphasised. The diagnosis is made earlier and with greater precision; standard therapeutic modalities are used less frequently and to a lesser degree; and measures directed at alleviation of specific anaesthetic and surgical causes are often possible. The outcome is generally good with the majority of patients leaving hospital alive and apparently well. The findings in this study are consistent with those of several large recent studies. ${ }^{1-5}$

\section{ACKNOWLEDGEMENTS}

The authors would like to thank all the anaesthetists in Australia and New Zealand who contributed to the 4000 incident reports upon which this and the other 24 papers in the Crisis Management Series are based. The coordinators of the project also thank Liz Brown for preparing the draft of the original Crisis Management Manual; Loretta Smyth for typing; Monika Bullock RN for earlier coding and classifying of data; Dr Charles Bradfield for the electronic version of the algorithms; Dr Klee Benveniste for literature research; and Drs Klee Benveniste, Michal Kluger, John Williamson and Andrew Paix for editing and checking manuscripts. Dr Craig Morgan carried out the initial detailed review of cardiac arrests in the AIMS database for this study and was first author of the initial draft of this paper. He declined authorship of the final draft and is thanked for having done the bulk of the original hard work.

\section{Authors' affiliations}

W B Runciman, Professor and Head, Department of Anaesthesia and Intensive Care, University of Adelaide and Royal Adelaide Hospital, Adelaide, South Australia, Australia

R W Morris, Director of Research and Development, Sydney Medical Simulation Centre, Royal North Shore Hospital, St Leonards, New South Wales, Australia

L M Watterson, Senior Staff Specialist and Director, Sydney Medical Simulation Centre, Royal North Shore Hospital, St Leonards, New South Wales, Australia

J A Williamson, Consultant Specialist, Australian Patient Safety Foundation and Visiting Research Fellow, University of Adelaide and Royal Adelaide Hospital, Adelaide, South Australia, Australia

A D Paix, Consultant Anaesthetist, Princess Royal University Hospital, Orpington, Kent, UK

This study was coordinated by the Australian Patient Safety Foundation, GPO Box 400, Adelaide, South Australia 5001, Australia.

\section{REFERENCES}

1 Sprung J, Warner ME, Contreras MG, et al. Predictors of survival following cardiac arrest in patients undergoing noncardiac surgery: a study of 518,294 patients at a tertiary referral center. Anesthesiology 2003:99:259-69.

2 Newland MC, Ellis SJ, Lydiatt CA, et al. Anesthetic-related cardiac arrest and its mortality: a report covering 72,959 anesthetics over 10 years from a US teaching hospital. Anesthesiology 2002;97:108-15.

3 Morray JP, Geiduschek JM, Ramamoorthy C, et al. Anesthesia-related cardiac arrest in children: initial findings of the Pediatric Perioperative Cardiac Arrest (POCA) Registry. Anesthesiology 2000;93:6-14.

4 Kawashima Y, Takahashi S, Suzuki M, et al. Anesthesia-related mortality and morbidity over a 5-year period in 2,363,038 patients in Japan. Acta Anaesthesiol Scand 2003:47:809-17.

5 Biboulet P, Aubas P, Dubourdieu J, et al. Fatal and non fatal cardiac arrests related to anesthesia. Can J Anaesth 2001;48:326-32

6 Morgan CA, Webb RK, Cockings J, et al. Cardiac arrest: an analysis of 2000 incident reports. Anaesth Intensive Care 1993;21:626-37.

7 Runciman WB, Webb RK, Klepper ID, et al. Crisis management: validation of an algorithm by analysis of 2000 incident reports. Anaesth Intensive Care 1993;21:579-92. 
8 Webb RK, Currie M, Morgan CA, et al. The Australian Incident Monitoring Study: an analysis of 2000 incident reports. Anaesth Intensive Care 1993;21:520-8.

9 Webb RK, van der Walt JH, Runciman WB, et al. Which monitor? An analysis of 2000 incident reports. Anaesth Intensive Care 1993:21:529-42.

10 Runciman WB, Kluger MT, Morris RW, et al. Crisis management during anaesthesia: the development of an anaesthetic crisis management manual Qual Saf Health Care 2005; 14:e1.

11 Watterson LM, Morris RW, Westhorpe RN, et al. Crisis management during anaesthesia: bradycardia. Qual Saf Health Care 2005; 14:e9.

12 Emergency Cardiac Care Committee and Subcommittees, American Heart Association. Guidelines for cardiopulmonary resuscitation and emergency cardiac care. Part III: Adult advanced cardiac life support. 1992 Nationa Conference on Cardiopulmonary Resuscitation (CPR) and Emergency Cardiac Care (ECC). JAMA 1992;268:2199-241.
13 The Advanced Life Support Committee of the Australian Resuscitation Council. Adult advanced life support algorithm, July 2002. Available at http://www.resus.org.au (accessed 12 September 2004).

14 The Advanced Life Support Committee of the Australian

Resuscitation Council. Paediatric advanced life support algorithm, March 2004. Available at http://www.resus.org.au (accessed 12 September 2004).

15 Fox MAL, Morris RW, Runciman WB, et al. Crisis management during regional anaesthesia. Qual Saf Health Care 2005; 14:e24.

16 Keenan RL, Boyan CP. Cardiac arrest due to anesthesia. A study of incidence and causes. JAMA 1985;253:2373-7.

17 Australian Patient Safety Foundation. Crisis Management Manual: COVER $A B C D$ A SWIFT CHECK. Adelaide: Australian Patient Safety Foundation, 1996, 74 pp. Available at http://www.apsf.net.au/anaesthesia.htm (accessed 6 September 2004). 